\title{
Determination of Acrylamide Levels in Infant Formulas and Baby Biscuits Sold in Turkey
}

\author{
Burhan Başaran 1,*(i), Ferid Aydın 2(D) \\ 1 Department of Travel, Tourism and Recreation Services, Ardeşen Vocational School, Recep Tayyip Erdogan University, \\ Rize 53100, Turkey; burhan.basaran@erdogan.edu.tr (B.B.); \\ 2 Department of Food Engineering, Faculty of Agriculture, Ataturk University, Erzurum 25100, Turkey; \\ feray@atauni.edu.tr (F.A.); \\ * Correspondence: burhan.basaran@erdogan.edu.tr (B.B.);
}

Scopus Author ID 57188724978

Received: 31.03.2021; Revised: 2.06.2021; Accepted: 5.06.2021; Published: 27.06.2021

\begin{abstract}
Babies are more vulnerable to both environmental and dietary contaminants compared to adults. Hence, the safety of baby foods deserves to be given top priority. In this study, the acrylamide level of 56 different baby foods ( 6 infant formula and 10 baby biscuit brands) which are widely consumed and have a high level of awareness in Turkey, has been determined and evaluated with LCMS/MS. Acrylamide level was measured in the range of $<\mathrm{LOQ}-578 \mu \mathrm{g} \mathrm{kg}^{-1}$ in infant formulas and $12.3-1,270 \mu \mathrm{g} \mathrm{kg}^{-1}$ in baby biscuits. The average acrylamide level in baby foods consumed by $0-5,6-$ 12 , and $>12$ months children were determined to be $45.1,62.5$, and $88.6 \mu \mathrm{g} \mathrm{kg}^{-1}$, respectively. The average acrylamide level of baby biscuits is $233 \mu \mathrm{g} \mathrm{kg}^{-1}$. The average acrylamide level corresponding to 1 portion/scale in infant formulas and biscuits was calculated as $0.30 \mu \mathrm{g} / 30 \mathrm{~mL}$ and $4.72 \mu \mathrm{g} / 20 \mathrm{~g}$, respectively. Research results can be used in acrylamide reduction and acrylamide exposure risk assessment studies.
\end{abstract}

Keywords: infant formula; baby biscuit; acrylamide; dietary acrylamide exposure; LC-MS/MS.

(C) 2021 by the authors. This article is an open-access article distributed under the terms and conditions of the Creative Commons Attribution (CC BY) license (https://creativecommons.org/licenses/by/4.0/).

\section{Introduction}

World Health Organization advises that infants need to be exclusively breastfed for the first 6 months and receive complementary foods in addition to breast milk until 24 months. In contrast, the rate of breastfeeding after childbirth is dropping dramatically worldwide [1]. Undoubtedly, many internal and external factors affect the mother's breastfeeding behavior [2]. In addition to the behavioral change caused by all these factors, mothers also provide other foods (especially packaged baby foods) for their children with or without breast milk, depending on their development [3].

Today, many companies are operating globally in the baby food industry [4]. It is possible to find many baby foods formulated to develop 0-6, 6-12, and >12 months children and enriched with various vitamins and minerals [5]. Baby foods are often preferred because of their easy accessibility and the practical preparation process [3]. However, it is also known that parents are seriously concerned about the composition, production, and safety of these foods [6]. Acrylamide is one of the compounds that cause this concern.

Acrylamide (2-propenamide, CAS No. 79-06-1) is a colorless, odorless, crystalline powder compound with low molecular weight $(71.08 \mathrm{kDa})$, easily soluble in water, ethanol, 
and acetone [7]. Acrylamide, which is highly used in areas such as dams, tunnels, water treatment, paper, and textiles [8], was first revealed in 2002 by Tareke et al. (2002) [9].

Acrylamide has a genotoxic and neurotoxic effect [10], and it was identified as a probable carcinogen for humans (Group 2A) by the International Agency for Research on Cancer (IARC) in 1994 [11]. Although there are findings in the literature that there is a positive relationship between acrylamide intake based on nutrition and cancer [12,13], studies indicating no relationship are also available $[14,15]$. Uncertainties regarding the formation process in acrylamide foods persist [16]. It has been stated that acrylamide is formed at high levels with heat treatment, especially in foods rich in asparagine amino acids and reducing sugar [9,17]. Although Maillard Reaction is accepted as the main mechanism in acrylamide formation, studies prove that acrolein, carnosine, B-alanine, aspartic acid, and pyruvic acid are transformed into acrylamide by various reactions $[18,19]$.

The European Commission and the Joint FAO/WHO Expert Committee on Food Additives stated that there is very little information on the level of acrylamide in foods and its formation, and advised to monitor and report systematically the exposure to foods containing high acrylamide and consumption of these foods [20-22]. The European Food Safety Authority (EFSA) conducted a study in the European Union in 2015 and reported that French fries, potato chips, bread, biscuits, breakfast cereals, coffee (dry), infant formula, and baby foods (processed cereal-based) contain 308 (303-313) $\mu \mathrm{g} \mathrm{kg}^{-1}, 389$ (388-389) $\mu \mathrm{g} \mathrm{kg}^{-1}, 42$ (36-49) $\mu \mathrm{g} \mathrm{kg}^{-1}, 265$ (261-269) $\mu \mathrm{g} \mathrm{kg}{ }^{-1}, 161$ (157-164) $\mu \mathrm{g} \mathrm{kg}^{-1}, 522$ (521-523) $\mu \mathrm{g} \mathrm{kg}^{-1}, 14$ (3-26) $\mu \mathrm{g} \mathrm{kg}^{-1}$, and 73 (7076) $\mu \mathrm{g} \mathrm{kg}^{-1}$ acrylamide, respectively. In the same study, it was stated that acrylamide exposure (P95) based on nutrition for infants, toddlers, other children, adolescents, adults, the elderly, and the very elderly changed in the range of 1.4-2.5, 1.4-3.4, 1.4-3.2, 0.9-2.0, 0.8-1.3, 0.7-1.0 $\mu \mathrm{g} / \mathrm{kg}$ bw per day, respectively [23]. Acrylamide levels in infant formula and baby foods are lower than those in other foods. However, the exposure to consumers (infants, toddlers) who target these foods is surprisingly higher than other consumer groups. Many researchers have also stated that children are exposed to acrylamide more because their body weight is lower than others and the variety of nutrition is limited [24-26].

In Turkey, approximately 1.2 million babies are born annually, and about 6.5 million children at the age ranging between 0 and 4 live [27]. It is stated that baby food consumption is at a low level in Turkey compared to other countries. However, the baby food market has almost always shown double-digit growth in the last 10 years, and it is expected to further grow in the future [28]. Studies have been conducted to determine acrylamide levels in baby food in Turkey [29-33]. However, the infant foods examined in the studies do not provide sufficient information in terms of both the number of samples and product details. This situation is mostly observed in other studies. For instance, the studies do not explain adequately which age group corresponds to infant formulas or acrylamide level of one portion for infant formula, and biscuits are not calculated according to the information given by the manufacturer on the packaging. It should be remembered that these data losses might adversely affect studies of dietary acrylamide exposure. Besides, it seems that recent studies were conducted in Turkey in 2013 and 2014. As it is known, the food sector is a very dynamic sector that constantly renews itself in the light of new information. Therefore, the period covering the last 7 years is sufficient for the occurrence of important changes in areas such as formulation and production technique of products.

In light of the current data in the literature, the exposure that starts with breast milk and infant formulas in the first months of the baby continues throughout life with changing 
nutritional habits according to the development of the individual. Therefore, knowing how and in what quantity and frequency we consume are closely related to public health. The aim of this study is to determine acrylamide levels in the consumption of different brands of baby food in Turkey that has a high level of awareness and consumption.

\section{Materials and Methods}

\subsection{Samples.}

In this study, infant formulas ( 6 popular brands) and baby biscuits (10 different popular brands) which are sold and consumed in Turkey, are examined. Infant formulas in Turkey are numbered as 1,2 , and 3 according to different age groups (0-6, 7-12, and >12 months). Total 56 baby foods (36 infant formulas and 20 baby biscuits) in their original packaging, including 2 products with different production dates representing each brand and number, were purchased from markets.

\subsection{Reagents and apparatuses.}

Acrylamide (99\%) and acrylamide- $\mathrm{d}_{3}$ were provided by Sigma-Aldrich (St. Louis, MO). Maxi-Spin filter tubes (0.45 $\mu \mathrm{m}$ PVDF) and HPLC grade acetonitrile, methanol, formic acid, n-hexane were obtained from ISOLAB (Wertheim, Germany). Oasis HLB (6 mL, 200 $\mathrm{mg}$ ) and Bond Elut-Accucat (200 mg, $3 \mathrm{~mL}$ ) SPE cartridges were supplied by Waters (Milford, MA) and Agilent Technologies (Inc. Folsom, CA, USA), respectively.

Liquid chromatography was carried out using a UPLC system (Agilent Technologies, model LC-1200 Infinity Series, Englewood, CO, USA) equipped with an autosampler. The Allegra X-30R centrifuge (Beckman Coulter, Palo Alto, CA) was equipped with a C0650 head. The analytical column used was a Zorbax Eclipse XDB-C18 (4.6 mm, $150 \mathrm{~mm}, 5-$ Micron) (Agilent Technologies, Loveland, CO, USA).

\subsection{Stock and working solution.}

Stock and working standards of acrylamide (99\%) and acrylamide- $\mathrm{d}_{3}$ were prepared in HPLC-grade water with $0.1 \%$ formic acid. Working standard solutions were prepared by diluting the stock solution of acrylamide. Stock and working solutions are stored at $4^{\circ} \mathrm{C}$ until use.

\subsection{Sample extraction.}

Samples of $1 \mathrm{~g}$ were weighed into a $50 \mathrm{~mL}$ centrifuge tube, and $9 \mathrm{~mL}$ water, $1 \mathrm{~mL}$ (100 $\mathrm{ng} \mathrm{mL} \mathrm{m}^{-1}$ ) of acrylamide- $\mathrm{d}_{3}$, and $5 \mathrm{~mL}$ hexane was added. The centrifuge tubes were shaken or vortexed for $3 \mathrm{~min}$ to mix contents. The tubes were centrifuged at $9000 \mathrm{rpm}$ for $15 \mathrm{~min}$. A pipet was used to transfer a $5 \mathrm{~mL}$ aliquot of the clarified aqueous layer to a filtration tube through a Maxi-Spin $0.45 \mu \mathrm{m}$ PVDF. The tubes were centrifuged at $6000 \mathrm{rpm}$ for $5 \mathrm{~min}$. Oasis HLB cartridges and A Bond Elut Accucat SPE cartridges were preconditioned with first 3.5 and 2.5 $\mathrm{mL} \mathrm{MeOH}$ and then 3.5 and $2.5 \mathrm{~mL}$ water, respectively. The solvents used for column conditioning were discarded. $1.5 \mathrm{~mL}$ of filtered extract was added to the Oasis HLB cartridge, then $0.5 \mathrm{~mL}$ water was used to wash the cartridge, and column eluent was discarded. Then 1.5 $\mathrm{mL}$ of water was loaded into the Oasis HLB cartridges, and the eluant was collected from the 
SPE cartridge. The first $0.5 \mathrm{~mL}$ of the eluent was discarded, and the remaining $1 \mathrm{~mL}$ of the extract was transferred to a vial [34].

\subsection{Analysis conditions.}

LC-MS/MS analysis conditions are shown in Table 1.

Table 1. LC-MS/MS analysis conditions

\begin{tabular}{l|l} 
Mobile phase A & $0.1 \%$ formic acid in water \\
\hline Mobile phase B & $0.1 \%$ formic acid in acetonitrile \\
\hline Mobile phase flow rate & $0.3 \mathrm{~mL} \mathrm{~min}^{-1}$ \\
\hline Source gas flow & $10 \mathrm{~L} \mathrm{~min}^{-1}$ \\
\hline Sheath gas flow & $10 \mathrm{~L} \mathrm{~min}^{-1}$ \\
\hline Nebulizing pressure & $40 \mathrm{psi}$ \\
\hline Capillary voltage & $4000 \mathrm{~V}$ \\
\hline Gas temperature & $350^{\circ} \mathrm{C}$ \\
\hline Sheath gas temperature & $325^{\circ} \mathrm{C}$ \\
\hline Column temperature & $30^{\circ} \mathrm{C}$ \\
\hline Injection volume & $10 \mu \mathrm{L}$
\end{tabular}

\subsection{Quality control.}

The linearity parameters, the limit of detection (LOD) and the limit of quantitation (LOQ), repeatability, reproducibility, and average recovery parameters were calculated to ensure the LC-MS's appropriateness/MS method for the analysis of acrylamide in baby foods. Linearity of the method was evaluated by building at seven standard solutions $(10,25,50,100$, $250,500,1000 \mathrm{ng} \mathrm{mL}^{-1}$ ) with $100 \mathrm{ng} \mathrm{mL}^{-1}$ of acrylamide-d3. In the calculation of the coefficient of determination $\left(\mathrm{R}^{2}\right)$, linear regression analysis was utilized. The limit of detection (LOD) and the limit of quantitation (LOQ) values were calculated. Method performance was evaluated by means of recovery experiments at different spiking levels (30 and $100 \mathrm{ng} \mathrm{mL}^{-1}$ ).

\section{Results and Discussion}

\subsection{Method verification.}

The calibration data fitted a linear regression model with a good value $\left(\mathrm{R}^{2}: 0.9997209\right)$ of coefficient of the range of $10-1000 \mathrm{ng} \mathrm{mL}^{-1}$ (Figure 1). The LOD and the LOQ values were calculated as 3.0 and $10.0 \mathrm{ng} \mathrm{mL}^{-1}$, respectively.

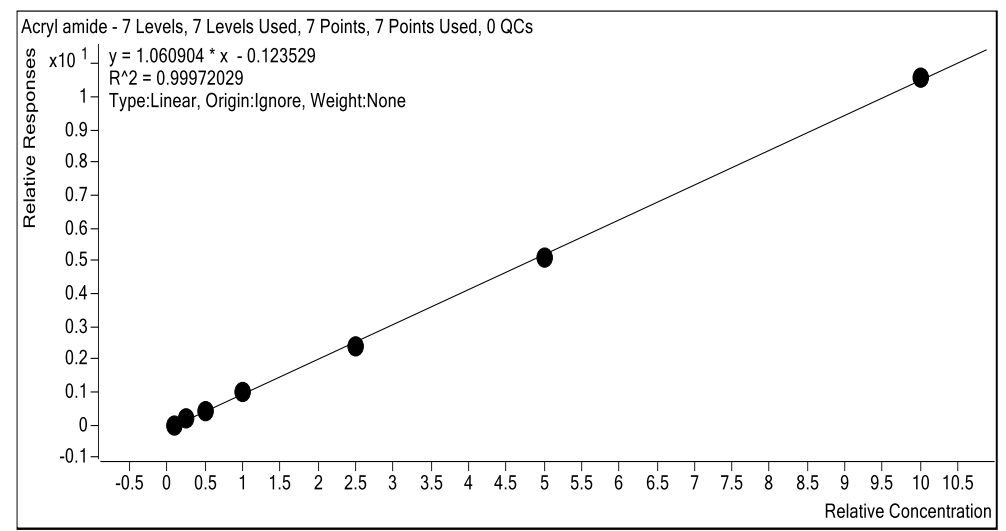

Figure 1. Calibration graph for baby foods spiked with acrylamide and acrylamide- $\mathrm{d}_{3}$ 
The method was verified for two food matrices. Acrylamide recovery was 93.1-97.4\% and $95.3-98.2 \%$ for baby food and baby biscuits, respectively. RSD was $<7 \%$ for all matrices evaluated (Table 2). The results were similar to other studies in the literature $[35,36]$. Thus, this method can be applied to the analysis.

Table 2. Average recovery values (R\%) and RSD (\%) obtained for acrylamide.

\begin{tabular}{l|l|l|l}
\multirow{2}{*}{ Food } & $\begin{array}{l}\text { Spike level } \\
\left(\mathbf{n g ~ g}^{-1}\right)\end{array}$ & $\begin{array}{l}\text { Repeatability } \\
(\mathbf{R} \pm \mathbf{R S D} \%)\end{array}$ & $\begin{array}{l}\text { Reproducibility } \\
(\mathbf{R} \pm \mathbf{R S D} \%)\end{array}$ \\
\hline \multirow{2}{*}{ Infant formula } & 30 & $93.1 \pm 4.3$ & $97.4 \pm 4.7$ \\
\cline { 2 - 4 } & 100 & $90.5 \pm 2,8$ & $95.2 \pm 4.3$ \\
\hline \multirow{2}{*}{ Baby biscuit } & 30 & $95.3 \pm 3.5$ & $98.2 \pm 5.3$ \\
\cline { 2 - 4 } & 100 & $94.6 \pm 4.1$ & $99.8 \pm 6.2$
\end{tabular}

The chromatograms of the fragment ions $\mathrm{m} / \mathrm{z} 58.20$ and 44.10 of the internal standard and $\mathrm{m} / \mathrm{z} 55.10$ and 44.10 for acrylamide in baby foods were used for quantification (Figure 2). Figure 3 illustrated the acrylamide chromatography of selected baby food. The retention time was determined to be $5.45 \mathrm{~min}$.
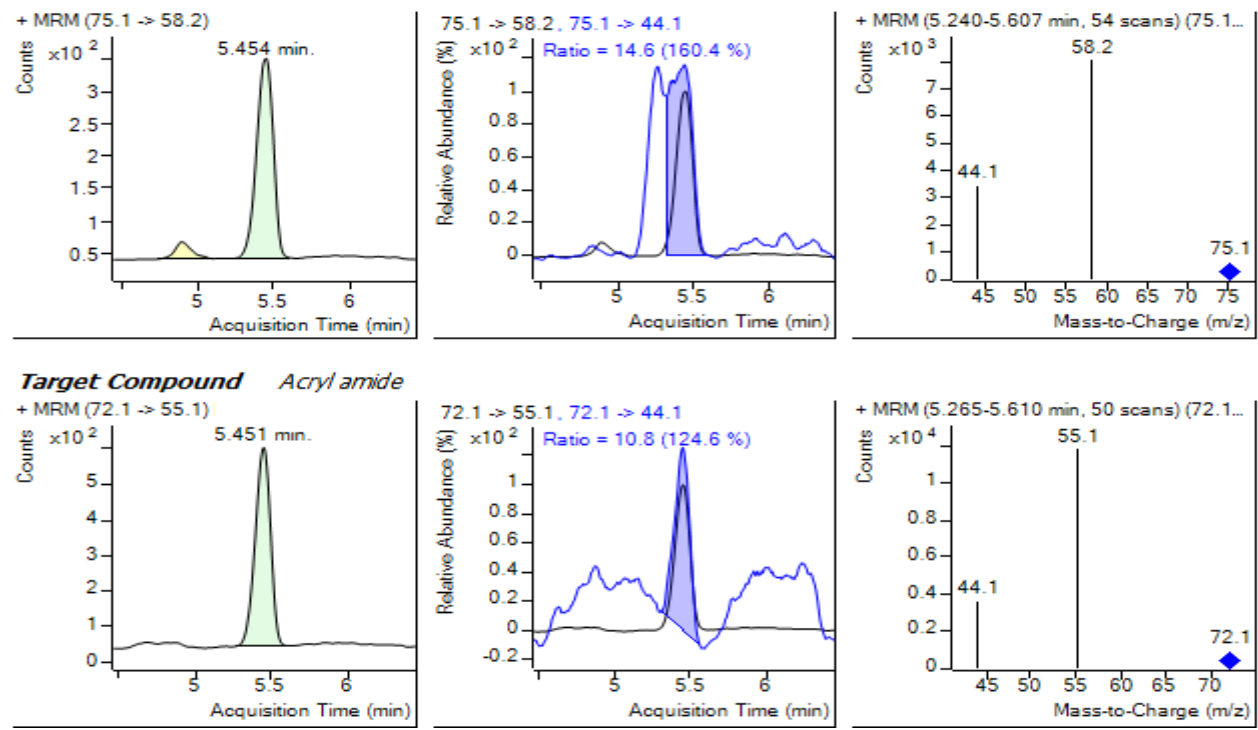

Figure 2. LC-MS/MS chromatogram of (a) acrylamide- $\mathrm{d}_{3}$ fragment ions m/z 58.20 and 44.10; (b) acrylamide fragment ions $\mathrm{m} / \mathrm{z} 55.10$ and 44.10 in infant formulas.

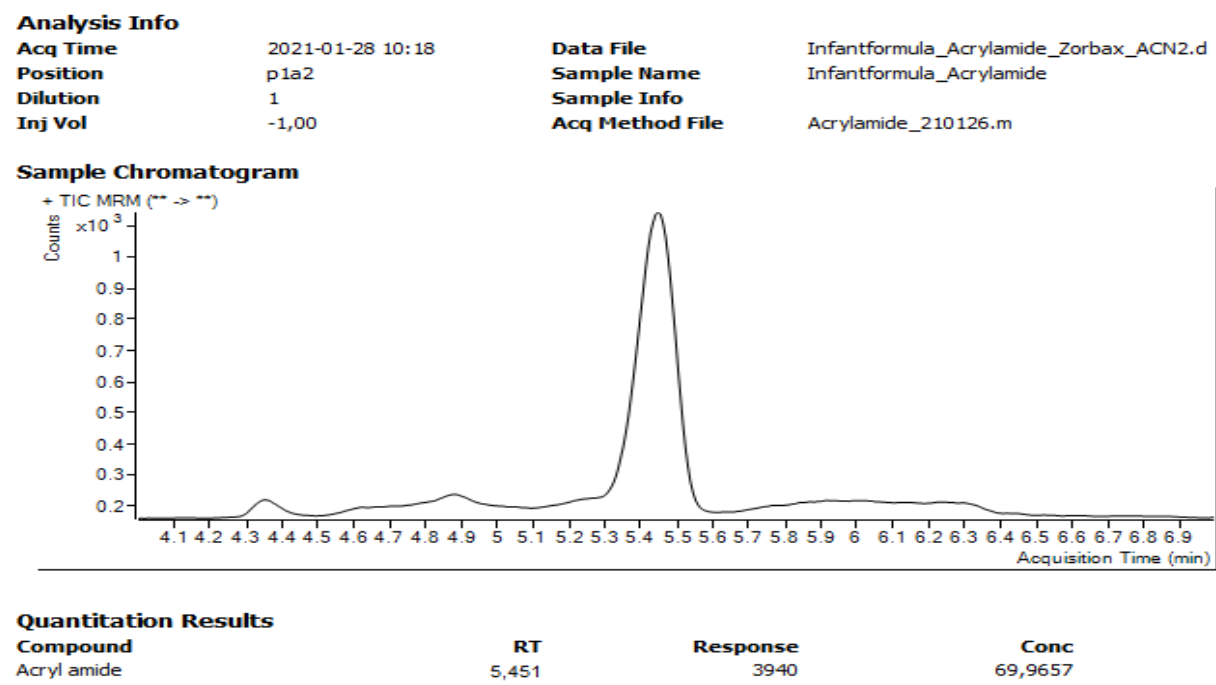

Figure 3. The acrylamide chromatography of selected infant formula. 
3.2. Acrylamide levels of baby foods.

Acrylamide levels and recommended 1 scale for consumption to the corresponding estimates in 6 brands and 18 different content in infant formula in Turkey are shown in Table 3.

Table 3. Acrylamide levels of infant formulas.

\begin{tabular}{l|l|l|l|l|l} 
Age groups/Brands & $\mathbf{N}$ & Range $\left(\boldsymbol{\mu g} \mathbf{~ k g}^{-1}\right)$ & Mean $\boldsymbol{\mu g} \mathbf{~ k g}^{-1}$ & $\boldsymbol{\mu g ~ 3 0 ~} \mathbf{~ L L}^{-1}$ & Note $^{\mathbf{b}}$ \\
\hline 0-6 months (Number 1) & \multicolumn{5}{|l}{} \\
\hline Brand 1 & 2 & $14.7-127$ & 48.0 & 0.21 & $4.30 \mathrm{~g}$ \\
\hline Brand 2 & 2 & $11.8-61.0$ & 31.2 & 0.14 & $4.50 \mathrm{~g}$ \\
\hline Brand 3 & 2 & $<$ LOQ-23.8 & 13.2 & 0.06 & $4.50 \mathrm{~g}$ \\
\hline Brand 4 & 2 & $15.4-135$ & 68.8 & 0.29 & $4.30 \mathrm{~g}$ \\
\hline Brand 5 & 2 & <LOQ-162 & 54.2 & 0.25 & $4.60 \mathrm{~g}$ \\
\hline Brand 6 & 2 & <LOQ-143 & 55.1 & 0.25 & $4.60 \mathrm{~g}$ \\
\hline & & Mean & 45.1 & 0.20 &
\end{tabular}

7-12 months (Number 2)

\begin{tabular}{l|l|l|l|l|l}
\hline Brand 1 & 2 & $<$ LOQ -140 & 65.3 & 0.29 & $4.50 \mathrm{~g}$ \\
\hline Brand 2 & 2 & $<$ LOQ -139 & 75.8 & 0.36 & $4.80 \mathrm{~g}$ \\
\hline Brand 3 & 2 & $13.6-55.8$ & 25.6 & 0.12 & $4.60 \mathrm{~g}$ \\
\hline Brand 4 & 2 & $18.2-228$ & 89.7 & 0.40 & $4.50 \mathrm{~g}$ \\
\hline Brand 5 & 2 & $25.6-188$ & 69.5 & 0.34 & $4.85 \mathrm{~g}$ \\
\hline Brand 6 & 2 & $23.8-142$ & 49.3 & 0.23 & $4.60 \mathrm{~g}$ \\
\hline & & Mean & 62.5 & 0.29 & \\
\hline
\end{tabular}

$>12$ months (Number 3)

\begin{tabular}{l|l|l|l|l|l}
\hline Brand 1 & 2 & $13.4-98.0$ & 52.7 & 0.21 & $4.00 \mathrm{~g}$ \\
\hline Brand 2 & 2 & $44.6-207$ & 103 & 0.49 & $4.80 \mathrm{~g}$ \\
\hline Brand 3 & 2 & $<$ LOQ-91.3 & 31.8 & 0.15 & $4.90 \mathrm{~g}$ \\
\hline Brand 4 & 2 & $21.9-578$ & 251 & 1.15 & $4.60 \mathrm{~g}$ \\
\hline Brand 5 & 2 & $14.6-102$ & 54.3 & 0.27 & $4.95 \mathrm{~g}$ \\
\hline Brand 6 & 2 & $19.2-70.4$ & 40.4 & 0.18 & $4.60 \mathrm{~g}$ \\
\hline & & Mean & 88.9 & 0.41 &
\end{tabular}

$\mathrm{N}$ : Number of samples, ${ }^{\text {a }}$ One scale is $30 \mathrm{~mL}$ - the information given by the producer on package,

${ }^{b}$ It is the amount that should be put on 1 scale according to the information given on the package by the manufacturer.

The acrylamide level in infant formula number 1 ( $0-6$ months) is in the range of $<\mathrm{LOQ}-$ $162 \mu \mathrm{g} \mathrm{kg}^{-1}$, and the average acrylamide level of all brands was found to be $45.1 \mu \mathrm{g} \mathrm{kg}^{-1}$. The average highest acrylamide level belongs to Brand $4\left(68.8 \mu \mathrm{g} \mathrm{kg}^{-1}\right)$. The average acrylamide level corresponding to 1 scale is $0.20(0.06-0.29) \mathrm{\mu g} \mathrm{kg}^{-1}$ (Table 3).

Brands 1 and 2 have the highest average acrylamide level in number 2 infant formula (7-12 months). The average acrylamide level of all products is $62.5 \mu \mathrm{g} \mathrm{kg}^{-1}$. The average acrylamide level corresponding to 1 scale is $0.29(0.12-0.40) \mu \mathrm{g} \mathrm{kg}^{-1}$ and the lowest acrylamide level was determined in Brand 3 (Table 3).

In infant formula, number 3 (>12 months), acrylamide level was in the range of $<$ LOQ$578 \mu \mathrm{g} \mathrm{kg}^{-1}$, and mean acrylamide level was determined as $88.9 \mu \mathrm{g} \mathrm{k} \mathrm{kg}^{-1}$. Brands with the highest and the lowest average acrylamide levels are Brand $4\left(251 \mu \mathrm{g} \mathrm{kg}^{-1}\right)$ and Brand $3(31.8$ $\left.\mu \mathrm{g} \mathrm{kg}^{-1}\right)$, respectively. The average acrylamide level corresponding to 1 scale is $0.41(0-15-$ 1.20) $\mu \mathrm{g} \mathrm{kg}^{-1}$ (Table 3).

When all the data in Table 3 were evaluated together, acrylamide level in infant formula was measured in the range of $\angle \mathrm{LOQ}-578 \mu \mathrm{g} \mathrm{kg}^{-1}$. The average acrylamide level of all infant formulas was measured as $69.9(13.2-251) \mu \mathrm{g} \mathrm{kg}^{-1}$. 1 scale corresponding to the acrylamide level was calculated as $0.30(0.06-1.20) \mu \mathrm{g} \mathrm{kg}^{-1}$. The acrylamide level of $8(11.1 \%)$ of the 72 samples analyzed were found below the LOQ value. As children get older, the acrylamide level 
in the infant formula they also consume increases. When acrylamide levels corresponding to 1 scale are compared, similarly, acrylamide level increases again in direct proportion to age. Undoubtedly, one factor contributing to this situation is the increase in the amount of infant formula added to 1 scale depending on age. Infant formulas with the lowest and the highest acrylamide levels are the same for all age groups and are Brand 3 and 4, respectively. It was not possible to reach a study showing the level of acrylamide in infant formulas consumed by children in Turkey. Similarly, infant formulas have been generally studied in other studies. Therefore, the comparison of the results obtained in this study with other studies was made in light of the data obtained for all infant formulas (all age groups) (Figure 5).

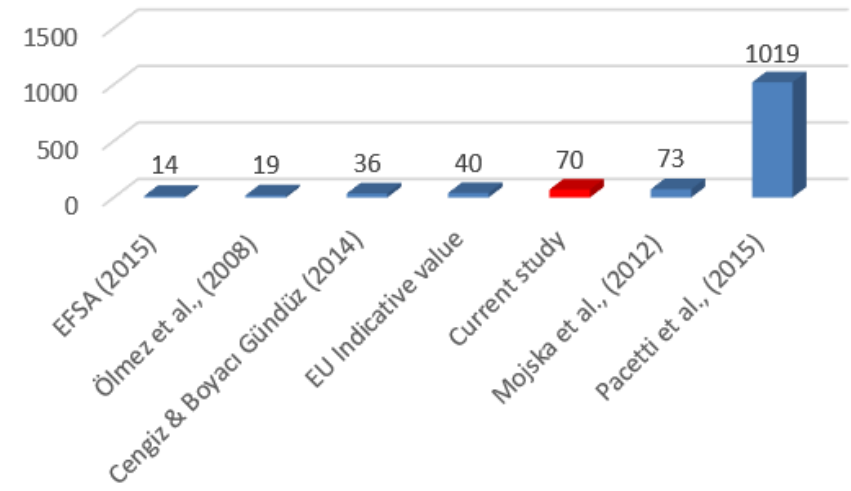

Figure 5. Average acrylamide levels in infant formulas in current research and other studies $\left(\mu \mathrm{g} \mathrm{kg}^{-1}\right)$.

It has been found that there are only two studies on the levels in infant formulas sold in Turkey, and the number of studies is quite limited. In these studies, acrylamide level was determined to be $19 \mu \mathrm{g} \mathrm{kg}^{-1}$ (8 samples) and $36 \mu \mathrm{g} \mathrm{kg}^{-1}$ ( 7 samples) by Ölmez et al. (2008) and Cengiz and Boyacı Gündüz (2014), in infant formulas of unknown age groups [30,32]. The European Commission (EC 2017/2158) determined the indicative acrylamide value in infant formulas to be $40 \mu \mathrm{g} \mathrm{kg-1}$ [20]. In other studies, the acrylamide level was found as $<5 \mu \mathrm{g} \mathrm{kg}^{-1}$ by Keramat et al. (2011), 73 (32-312) $\mathrm{g} \mathrm{kg} \mathrm{k}^{-1}$ by Mojska et al. (2012), and in one scale it was $0.32(0.13-1.38) \mu \mathrm{g} \mathrm{kg}^{-1}$, Pacetti et al. (2015) determined as 1.019 (<LOQ-1.821) $\mathrm{\mu g} \mathrm{kg}^{-1}$, EFSA (2015) as 14 (3-26) $\mu \mathrm{g} \mathrm{kg}^{-1}$ and Lambert et al. (2018) determined it as $0.60-2.90 \mu \mathrm{g} \mathrm{kg}^{-}$ ${ }^{1}[23,25,36-38]$.

The acrylamide levels and estimated values corresponding to the recommended consumption in baby biscuits that are commercially available in Turkey with 10 brands and 20 different content are shown in Table 4.

Table 4. Acrylamide levels of baby biscuits.

\begin{tabular}{|c|c|c|c|c|c|}
\hline Brands & $\mathbf{N}$ & Range $\left(\mu \mathrm{g} \mathrm{kg}^{-1}\right)$ & Mean $\mu \mathrm{g} \mathrm{kg}^{-1}$ & 1 portion $^{c}$ & Note \\
\hline Brand 1 & 2 & $32.7-179$ & 96.7 & 1.93 & From 4 months \\
\hline Brand 2 & 2 & $78.2-1,270$ & 608 & 12.16 & From 6 months \\
\hline Brand 3 & 2 & $17.5-176$ & 91.9 & 1.84 & From 6 months \\
\hline Brand 4 & 2 & 26.1-299 & 185 & 3.69 & From 6 months \\
\hline Brand 5 & 2 & $24.2-121$ & 75.1 & 1.50 & From 6 months \\
\hline Brand 6 & 2 & $12.3-840$ & 250 & 6.25 & From 6 months \\
\hline Brand 7 & 2 & $39.6-510$ & 193 & 4.83 & From 6 months \\
\hline Brand 8 & 2 & $52.0-1,064$ & 431 & 7.00 & From 6 months \\
\hline Brand 9 & 2 & $59.3-131$ & 89.4 & 1.79 & From 6 months \\
\hline \multirow[t]{2}{*}{ Brand 10} & 2 & $63.8-1,020$ & 311 & 6.21 & From 6 months \\
\hline & & Mean & 233 & 4.72 & \\
\hline
\end{tabular}

$\mathrm{N}$ : Number of samples,

${ }^{\mathrm{c}}$ One portion includes 4-5 biscuits ( $20 \mathrm{~g}$ ) - the information given on the package by the manufacturer. 
The acrylamide level in baby biscuits has a very wide range from 12.3 to $1,270 \mu \mathrm{g} \mathrm{kg}^{-}$ ${ }^{1}$. The average acrylamide level of all baby biscuits was determined to be $233 \mu \mathrm{g} \mathrm{kg}^{-1}$. The first three baby biscuit brands with the highest average acrylamide level are Brand $2\left(608 \mu \mathrm{g} \mathrm{kg}^{-1}\right)$, Brand $8\left(431 \mu \mathrm{g} \mathrm{kg}^{-1}\right)$, and Brand $10\left(311 \mu \mathrm{g} \mathrm{kg}^{-1}\right)$, respectively. The lowest average acrylamide level is Brand $5\left(75.06 \mu \mathrm{g} \mathrm{kg}^{-1}\right)$. The acrylamide level corresponding to 1 portion is between $1.50-12.2 \mu \mathrm{g} \mathrm{kg}^{-1}$, and the average acrylamide level is calculated as $4.72 \mu \mathrm{g} \mathrm{kg}^{-1}$. The comparison of the average acrylamide level detected in baby biscuits in this study with other studies is shown in Figure 6.

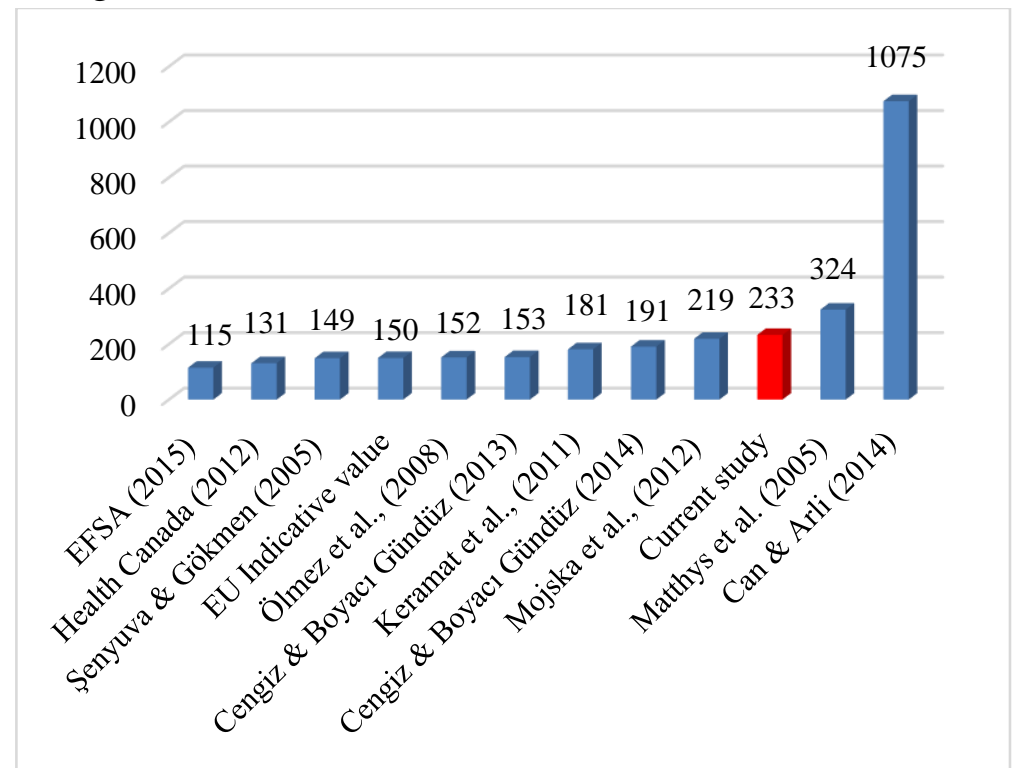

Figure 6. Average acrylamide levels in baby biscuits in current research and other studies $\left(\mu \mathrm{g} \mathrm{kg}^{-1}\right)$.

The acrylamide level in baby biscuits sold in Turkey was determined to be $149 \mathrm{\mu g} \mathrm{kg}^{-1}$ (3 samples) by Şenyuva and Gökmen (2005), $152 \mu \mathrm{g} \mathrm{kg}^{-1}$ (3 marks-14 samples) by Ölmez et al. (2008), $153 \mu \mathrm{g} \mathrm{kg}^{-1}$ (3 brands-33 samples) and $191 \mu \mathrm{g} \mathrm{kg}^{-1}$ (10 samples) by Cengiz and Boyac1 Gündüz $(2013 ; 2014)$, respectively and $1,075(490-1,660) \mu \mathrm{g} \mathrm{kg}^{-1}$ by Can and Arli (2014) [29-33]. The European Commission (EC 2017/2158) has determined the indicative acrylamide value for baby biscuits consumed by infants and young children to be $150 \mu \mathrm{g} \mathrm{kg}-1$ [20]. In other studies, Matthys et al. (2005) determined it to be $324(225-1,217) \mu \mathrm{g} \mathrm{kg}^{-1}$, Keramat et al. (2011) $181 \mathrm{\mu g} \mathrm{kg}^{-1}$, Health Canada (2012) 131 (119-139) $\mathrm{ug} \mathrm{kg}^{-1}$, Mojska et al. (2012) 219 (37-516) $\mu \mathrm{g} \mathrm{kg}$, and in one portion (25 g) it was $5.50(0.93-12.90) \mu \mathrm{g} \mathrm{kg}^{-1}$, Michalak et al. (2013) 10.8-61.2 $\mu \mathrm{g} \mathrm{kg}^{-1}$ (cereal-based baby foods), EFSA (2015) $115 \mu \mathrm{g} \mathrm{kg}^{-1}$ and Lambert et al. (2018) 11-17 $\mu \mathrm{g} \mathrm{kg}^{-1}$ (cereal-based baby foods) [23,25,37-41].

\section{Conclusions}

In this research, we focused on infant foods, which have an important place in the nutrition of the most vulnerable individuals, namely children. The acrylamide level has a very wide range of baby food and biscuits. In general, a relatively higher acrylamide level was determined in the study compared to other studies, especially in the indicative values determined by the European Commission in both baby food and baby biscuits. This situation is related to the type, amount, and process conditions of the raw material used in the product formulation. Our research is one of the most comprehensive studies in Turkey that determine and assess the acrylamide level in baby foods and biscuits. The study is considered a good resource for risk assessment studies of acrylamide exposure from infant foods. More studies 
need to be conducted, including other types of baby foods in Turkey, where the baby food market constantly grows.

\section{Funding}

This work was funded by Atatürk University Coordination Center of Scientific Research Projects [FBA-2020-8292].

\section{Acknowledgments}

This study was carried out in the laboratories of the Eastern Anatolia Advanced Technologies Research and Application Center (DAYTAM).

\section{Conflicts of Interest}

The authors declare no conflict of interest.

\section{References}

1. Country implementation of the International Code of Marketing of Breast-milk Substitutes: WHO status report. Available online: https://apps.who.int/iris/bitstream/handle/10665/85621/9789241505987_eng.pdf (accessed on 19 March 2021).

2. Hamilton, W.N. Factors influencing maternal decision-making on infant feeding practices. In Infant feeding: breast versus formula, 1nd ed.; Al-Zwaini, J.I., Al-Ani, R.Z., Hurley, W., Eds.; Publisher: IntechOpen, Croatia, 2020, 1-14, https://doi.org/10.5772/intechopen.91325.

3. Başaran, B. The evaluation of childhood foods and infant formula exposure to furan, chloropropanols and acrylamide contamination by food processing. In Infant feeding: breast versus formula, 1nd ed.; Al-Zwaini, J.I., Al-Ani, R.Z., Hurley, W., Eds.; Publisher: IntechOpen, Croatia, 2020, 1-15, https://doi.org/10.5772/intechopen.93417.

4. Hastings, G.; Angus, K.; Eadie, D.; Hunt, K. Selling second best: how infant formula marketing works. Globalization and Health 2020, 16, 1-12, https://doi.org/10.1186/s12992-020-00597-w.

5. Traves, D. Understanding infant formula. Paediatrics and Child Health 2019, 29, 384-388.

6. Lee, E. Health, morality, and infant feeding: British mothers' experiences of formula milk use in the early weeks. Sociology of Health \& Illness 2007, 29, 1075-1090, https://doi.org/10.1111/j.14679566.2007.01020.x.

7. Acrylamide. Available online: http://www.inchem.org/documents/pims/chemical/pim652.htm\#PartTitle:1.\%20\%20NAME (accessed on 23 March 2021).

8. Kumar, J.; Das, S.; Teoh, S.L. Dietary acrylamide and the fisks of developing cancer: facts to ponder. Frontiers in Nutrition 2018, 5, 1-12, https://doi.org/10.3389/fnut.2018.00014.

9. Tareke, E.; Rydberg, P.; Karlsson, P.; Eriksson, S.; Törnqvist, M. Analysis of acrylamide, a carcinogen formed in heated foodstuffs. Journal of Agricultural and Food Chemistry 2002, 50, 4998-5006, https://doi.org/10.1021/jf020302f.

10. Koszucka, A.; Nowak, A.; Nowak, I.; Motyl, I. Acrylamide in human diet, its metabolism, toxicity, inactivation and the associated European Union legal regulations in food industry. Critical Reviews in Food Science and Nutrition 2020, 60,1677-1692, https://doi.org/10.1080/10408398.2019.1588222.

11. IARC monographs on the identification of carsinogenic hazards to humans. Available online: https://monographs.iarc.fr/list-of-classifications (accessed on 15 March 2021).

12. Adani, G.; Filippini, T.; Wise, L.A.; Halldorsson, T.I.; Blaha, L.; Vinceti, M. Dietary intake of acrylamide and risk of breast, endometrial, and ovarian cancers: a systematic review and dose-response metaanalysis. Cancer Epidemiology and Prevention Biomarkers 2020, 29, 1095-1106, https://doi.org/10.1158/1055-9965.EPI-19-1628.

13. Atabati, H.; Abouhamzeh, B.; Abdollahifar, M.A.; Javadinia, S.S.; Gharibian Bajestanie, S.; Atamaleki, A.; Raoofi, A.; Fakhri, Y.; Oliveira, F.A.C.; Khaneghah, A.M. The association between high oral intake of 
acrylamide and risk of breast cancer: An updated systematic review and meta-analysis. Trends in Food Science \& Technology 2020, 100, 155-163, https://doi.org/10.1016/j.tifs.2020.04.006.

14. McCullough, M.L.; Hodge, R.A.; Um, C.Y.; Gapstur, S.M. Dietary acrylamide is not associated with renal cell cancer risk in the CPS-II nutrition cohort. Cancer Epidemiology and Prevention Biomarkers 2019, 28, 616-619, https://doi.org/10.1158/1055-9965.EPI-18-0909.

15. Kito, K.; Ishihara, J.; Kotemori, A.; Zha, L.; Liu, R.; Sawada, N.; Iwasaki, M.; Sobue, T.; Tsugane, S. Dietary acrylamide intake and the risk of pancreatic cancer: the Japan public health center-based prospective study. Nutrients 2020, 12, 3584, https://doi.org/10.3390/nu12113584.

16. Semla, M.; Goc, Z.; Martiniaková, M.; Omelka, R.; Formicki, G. Acrylamide: a common food toxin related to physiological functions and health. Physiological Research 2017, 66, 205-217, https://doi.org/10.33549/physiolres.933381.

17. Yaylayan, V.A.; Stadler, R.H. Acrylamide formation in food: a mechanistic perspective. Journal of AOAC International 2005, 88, 262-267, https://doi.org/10.1093/jaoac/88.1.262.

18. Arvanitoyannis, I.S.; Dionisopoulou, N. Acrylamide: formation, occurrence in food products, detection methods, and legislation. Critical Reviews in Food Science and Nutrition 2014, 54, 708-733, https://doi.org/10.1080/10408398.2011606378.

19. Zhang, Y.; Zhang, Y. Formation and reduction of acrylamide in Maillard reaction: a review based on the current state of knowledge. Critical Reviews in Food Science and Nutrition 2007, 47, 521-542, https://doi.org/10.1080/10408390600920070.

20. European Commission Regulation (EU) 2017/2158 of 20 November 2017 establishing mitigation measures and benchmark levels for the reduction of the presence of acrylamide in food. 2017.

21. European Commission Recommendation (EU) 2019/1888 of 7 November 2019 on the monitoring of the presence of acrylamide in certain foods. 2019.

22. Evaluation of certain contaminants in food: Seventy-second report of the Joint FAO/WHO Expert Committee on Food Additives. WHO Technical Report Series. 959. 2011.

23. European Food Safety Authority. Scientific opinion on acrylamide in food. EFSA Journal 2015, 13, 4104, https://doi.org/10.2903/j.efsa.2015.4104.

24. Sirot, V.; Rivière, G.; Leconte, S.; Vin, K.; Traore, T.; Jean, J.; Carne, G.; Gorecki, S.; Veyrand, B.; Marchand, P.; Le Bizec, B.; Jean-Pierre, C.; Feidt, C.; Vasseur, P.; Lambert, M.; Inthavong, C.; Guerin, T.; Hulin, M. French infant total diet study: Dietary exposure to heat-induced compounds (acrylamide, furan and polycyclic aromatic hydrocarbons) and associated health risks. Food and Chemical Toxicology 2019, 130, 308-316, https://doi.org/10.1016/j.fct.2019.05.009.

25. Mojska, H.; Gielecińska, I.; Stoś, K. Determination of acrylamide level in commercial baby foods and an assessment of infant dietary exposure. Food and Chemical Toxicology 2012, 50, 2722-2728, https://doi.org/10.1016/j.fct.2012.05.023.

26. Branciari, R.; Roila, R.; Ranucci, D.; Altissimi, M.S.; Mercuri, M.L.; Haouet, N.M. Estimation of acrylamide exposure in Italian schoolchildren consuming a canteen menu: health concern in three age groups. International Journal of Food Sciences and Nutrition 2020, 71, 122-131, https://doi.org/10.1080/09637486.2019.1624692.

27. Turkey's population. Available online: https://biruni.tuik.gov.tr/medas/?kn=206\&locale=tr (accessed on 19 March 2021).

28. Baby economy. Available online: https://www.ekonomist.com.tr/kapak-konusu/bebek-ekonomisi-2.html (accessed on 25 March 2021).

29. Şenyuva, H.Z.; Gökmen, V. Survey of acrylamide in Turkish foods by an in-house validated LC-MS method. Food Additives and Contaminants 204-209, https://doi.org/10.1080/02652030512331344178.

30. Ölmez, H.; Tuncay, F.; Özcan, N.; Demirel, S. A survey of acrylamide levels in foods from the Turkish market. Journal of Food Composition and Analysis 2008, 21, 564-568, https://doi.org/10.1016/j.jfca.2008.04.011.

31. Cengiz, M.F.; Gündüz, C.P.B. Acrylamide exposure among Turkish toddlers from selected cereal-based baby food samples. Food and Chemical Toxicology 2013, 60, 514-519, https://doi.org/10.1016/j.fct.2013.08.018.

32. Cengiz, M.F.; Boyacı Gündüz, C.P. An eco-friendly, quick and cost-effective method for the quantification of acrylamide in cereal-based baby foods. Journal of the Science of Food and Agriculture 2014, 94,25342540, https://doi.org/10.1002/jsfa.6592. 
33. Can, N.O.; Arli, G. Analysis of acrylamide in traditional and nontraditional foods in turkey using HPLCDAD with spe cleanup. Journal of Liquid Chromatography \& Related Technologies 2014, 37, 850-863, https://doi.org/10.1080/10826076.2012.758148.

34. Roach, J.A.; Andrzejewski, D.; Gay, M.L.; Nortrup, D.; Musser, S.M. Rugged LC-MS/MS survey analysis for acrylamide in foods. Journal of Agricultural and Food Chemistry 2003, 51, 7547-7554, https://doi.org/10.1021/jf0346354.

35. Lee, K.J.; Lee, G.H.; Kim, H.; Oh, M.S.; Chu, S.; Hwang, I.J.; Park, H.M. Determination of heterocyclic amines and acrylamide in agricultural products with liquid chromatography-tandem mass spectrometry. Toxicology Research 2015, 31, 255-264, https://doi.org/10.5487/TR.2015.31.3.255.

36. Pacetti, D.; Gil, E.; Frega, N.G.; Álvarez, L.; Dueñas, P.; Garzón, A.; Lucci, P. Acrylamide levels in selected Colombian foods. Food Additives \& Contaminants: $\quad$ Part $\quad B \quad \mathbf{2 0 1 5}, \quad 8, \quad 99-105$, https://doi.org/10.1080/19393210.2014.995236.

37. Keramat, J.; LeBail, A.; Prost, C.; Soltanizadeh, N. Acrylamide in foods: chemistry and analysis. a review. Food and Bioprocess Technology 2011, 4, 340-363, https://doi.org/10.1007/s11947-010-0470-x.

38. Lambert, M.; Inthavong, C.; Hommet, F.; Leblanc, J.C.; Hulin, M.; Guérin, T. Levels of acrylamide in foods included in 'the first French total diet study on infants and toddlers'. Food Chemistry 2018, 240, 997-1004, https://doi.org/10.1016/j.foodchem.2017.08.035.

39. Health Canada's revised exposure assessment of acrylamide in food. Bureau of Chemical Safety. Food Directorate. Health Products and Food Branch. Available online: https://www.canada.ca/content/dam/hcsc/migration/hc-sc/fn-an/alt_formats/pdf/securit/chem-chim/food-aliment/acrylamide/rev-eval-exposureexposition-eng.pdf (accessed on 21 March 2021).

40. Matthys, C.; Bilau, M.; Govaert, Y.; Moons, E.; De Henauw, S.; Willems, J.L. Risk assessment of dietary acrylamide intake in Flemish adolescents. Food and Chemical Toxicology 2005, 43, 271-278, https://doi.org/10.1016/j.fct.2004.10.003.

41. Michalak, J.; Gujska, E.; Kuncewicz, A. RP-HPLC-DAD studies on acrylamide in cereal-based baby foods. Journal of Food Composition and Analysis 2013, 32, 68-73, https://doi.org/10.1016/j.jfca.2013.08.006. 